\title{
A Case Series: Non-vascularized Autologous Fibular Graft in the Treatment of Major Segmental Bone Defect after Post-traumatic at Diaphyseal Femur
}

\author{
Hidayat Siregar $^{1 *(\mathbb{D})}$, Rahmad Gunawan ${ }^{2}$ Didi Fitriadi $^{2}$ (D) \\ ${ }^{1}$ Department of Orthopaedics and Traumatology, Lower Division, Faculty of Medicine, University of Sumatera Utara, Haji Adam \\ Malik General Hospital, Medan, Indonesia; ${ }^{2}$ Department of Orthopaedics and Traumatology, Faculty of Medicine, University of \\ Sumatera Utara, Haji Adam Malik General Hospital, Medan, Indonesia
}

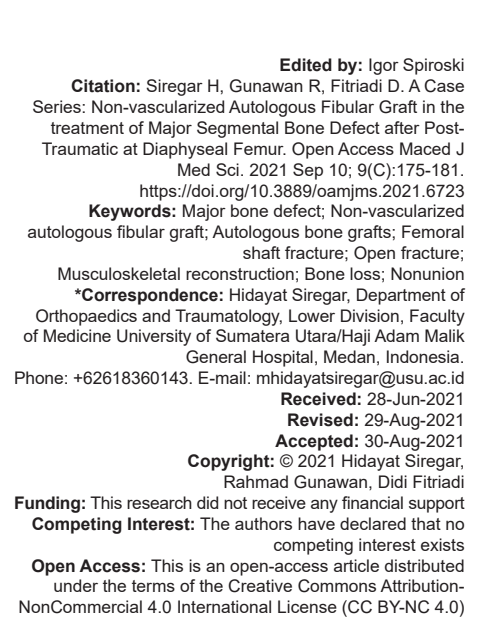

\section{Introduction}

Fractures resulting in segmental bone loss are very challenging for the orthopedic surgeon, These are commonly seen as the result of increasing civil strife and motor vehicular accidents. Non-vascularized fibula graft and cancellous bone grafting provide a reliable means of treating such conditions in developing countries. Orthopedic surgeons in developed countries have the option of choosing vascularized bone transfers, bone transport, allogenic bone grafts, bone graft substitutes, and several other means to treat such conditions, however, in developing countries where such facilities or expertise may not be readily available, the surgeon has to rely on other techniques of treatment. The aim of this case series is to determine the efficacy of the use of nonvascularized fibular grafts to re-establish bone continuity for the purpose of weight-bearing in lower limbs. This old-age technique first reported in 1911 [1], [2]. Fractures with segmental bone loss are more likely to be open and often occur because of high-energy trauma.

\begin{abstract}
BACKGROUND: In the management of bony defects, autologous bone grafts can be used as the mechanical used to the treat large post traumatic defects caused by high-energy trauma with open fracture and nonunion cases cases. Here we would like to present a 16-year-old woman and a 37-year-old man patients of majo MATERIAL AND METHODS: We treat post-traumatic of the major bone defect at the femoral shaft region with $9 \mathrm{~cm}$ S. The patient has a good result with good functional outcome after open reduction internal fixation (ORIF) CONCLUSION: Complete and comprehensive ORIF with autologous non- vascularized fibular graft, stabilized fracture by LC-DCP for $1^{\text {st }}$ patient and femoral locking plate for $2^{\text {nd }}$ patient allowing early rehabilitation and early mobilization resulting better outcome for the patient. This treatment can be accepted at the hospitals with limited facilities and health professionals to manage bone defects in open shaft femoral fractures to achieved union, preserved length and motion with no donor site morbidity, giving patients good functional outcome and radiologic result with less cost.
\end{abstract}

Among the autograft and allograft reconstructions, it can be done either as vascularized or non-vascularized graft [3], [4]. The advantage of using vascularized graft is rapid biological incorporation, good growth potential, and the ability to thrive in compromised soft tissue, however, these require technical expertise, specific tools for operation, and complete facilities. The long-term follow-up of non-vascularized fibular graft also gives good result [3].

Several surgical methods are available for bridging such defects, many studies have demonstrated the clinical usefulness of autogenous cortical bone reconstruction, but resorption of bone and fractures of the graft are possible complications [5], [6]. Operative procedures involving non-vascularized autogenous bone grafts may be unsuitable because their success depends on the age and ability of the surrounding soft tissues to withstand the operative manipulation and to revascularized the transplanted bone graft. Although free vascularized bone grafts have been advocated recently [7]. The older methods of bridging these gaps with autogenous nonvascularized bone grafts are still successful [5]. The free 
vascularized osteo-cutaneous fibular graft has been recommended as a useful treatment modality for the reconstruction of extensive tibial defects combined with soft tissue injury, non-vascularized bone graft is effective only for short bone defects $(<5-6 \mathrm{~cm})$ [8], [9], [10]. The purpose of our study is to describe our experience treating major bone defect using non-vascularized fibular autogenous grafts that were used for the reconstruction of posttraumatic in large bone defect.

\section{Case Report}

\section{Case 1}

A 16-year-old female patient was admitted to our emergency department after got a Traffic Accident using motorcycle, The trauma had broken the posterolateral aspect of his right thigh and shattered the femoral diaphysis. Bone splinters had lacerated the surrounding muscles and the skin on the anteromedial aspect of the thigh. This open fracture is classified as a Gustilo III A and involved one-third of the femoral shaft length (Figure 1).

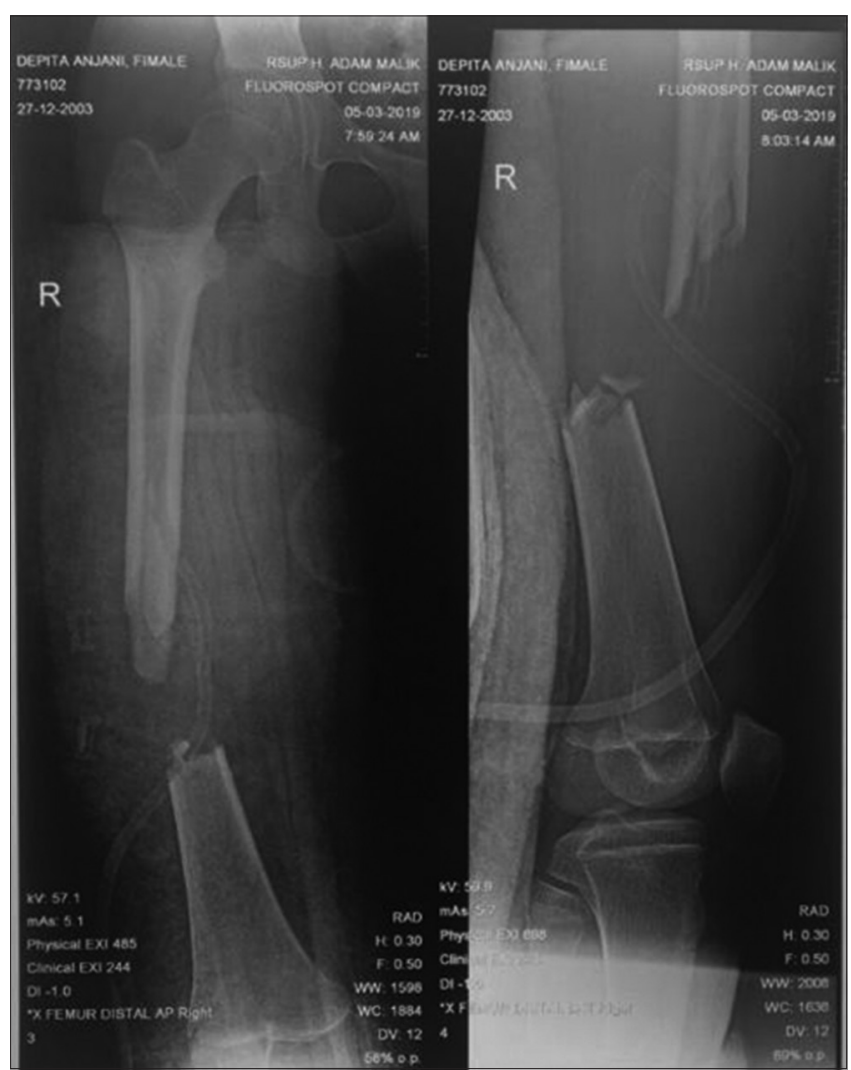

Figure 1: Gap femoral shaft fracture $7 \mathrm{~cm}$

Despite the effect of open wound that produced by a high-speed injury when it goes through tissues, there was no sign of vascular or neural injury, and peripheral pulses were palpable at inguinal artery, popliteal artery, dorsalis pedis artery, tibialis anterior artery, tibialis posterior artery, all fingers saturation are $98 \%$. This patient with Transverse fracture with a combined bone, muscle, and skin defect about $15 \times 8 \mathrm{~cm}$ with muscle-based.
Skin traction and debridement were chosen as a first-line treatment, the wound was largely exposed and debrided and the wound was left open, for the treatment of open wounds, to prevent further infection. After 2 weeks the wound was re-debrided and primarily closed.

One month after the initial injury the tissue had healed sufficiently to consider a reconstruction, there was no evidence of infection. Non-vascularized autologous fibular graft with the Internal fixation with limited contact dynamic compression plate (LC-DCP) method were considered. Immediate reconstruction with a massive bone autograft was preferred because it would allow rapid weight-bearing.

A $9 \mathrm{~cm}$ non-vascularized fibular graft (Figure 2) was fixed by an internal fixation LC-DCP (Figure 3). The length of the reconstruction was based on the opposite femur.
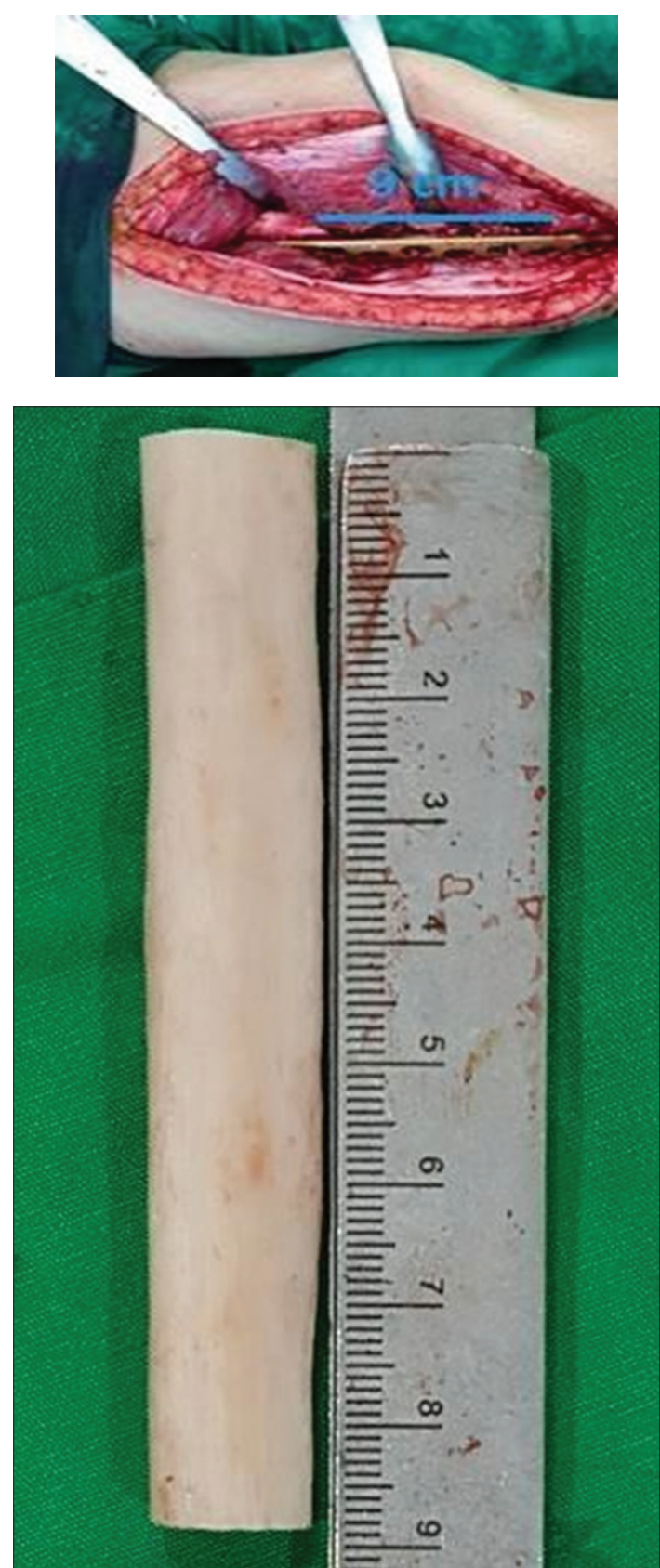

Figure 2: $9 \mathrm{~cm}$ non-vascularized fibular graft 


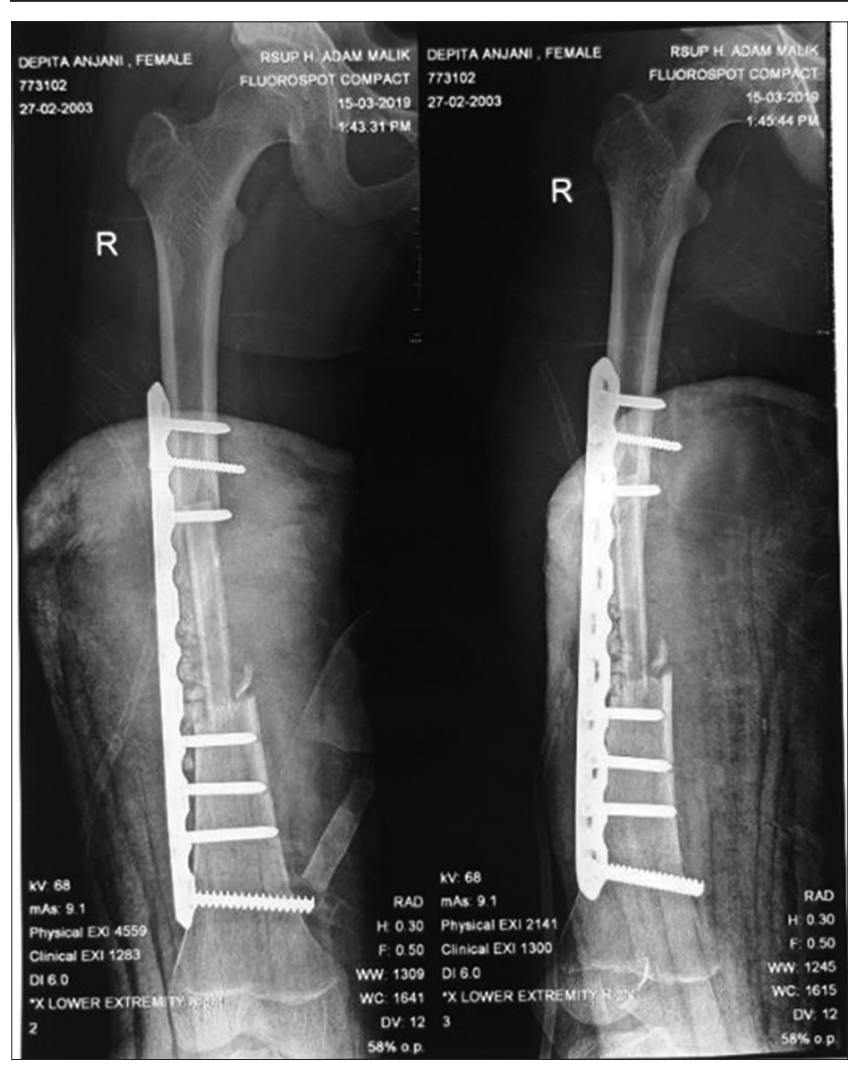

Figure 3: Internal fixation long locking plate suction drain

The different tissue layers were closed over a

After a short stay in the hospital, the patient recovered gradually from surgery, and physiotherapy was immediately started, He was discharged nonweight-bearing for 2 weeks postoperatively.

The first signs of bone healing were evident on radiographs at 8 weeks, 8 weeks after operation the results of the control femur $x$-ray if comparable 2 months ago, are currently installed plates and screws in onethird of proximal to one-third of the distal femur, the position of the bone fragments is smoothly performed using a bone graft begins to show periosteal reactions minimal appearance (Figure 4).

Final follow-up found in 32 weeks radiographs (Figure 5) showed consolidation and the bridging achieved of the femoral diaphyseal shaft with definite Fibula in bridging the Femoral defect, the patient has a good range of movement of the hip and knee (Table 1) and there is no leg length discrepancy nor atrophy (Table 2) (Figure 6).

In order to fasten the bone healing, physiotherapy was performed to increase mobilization and muscle strength.

The motor vehicle accident impacted on his thigh, causing a segmental fracture in his right middle femoral shaft.

There was no open wound or any neurovascular injury during inspection and the patient was scheduled for two operations in two different days. The right femur underwent open reduction and internal fixation using a plate and screw.

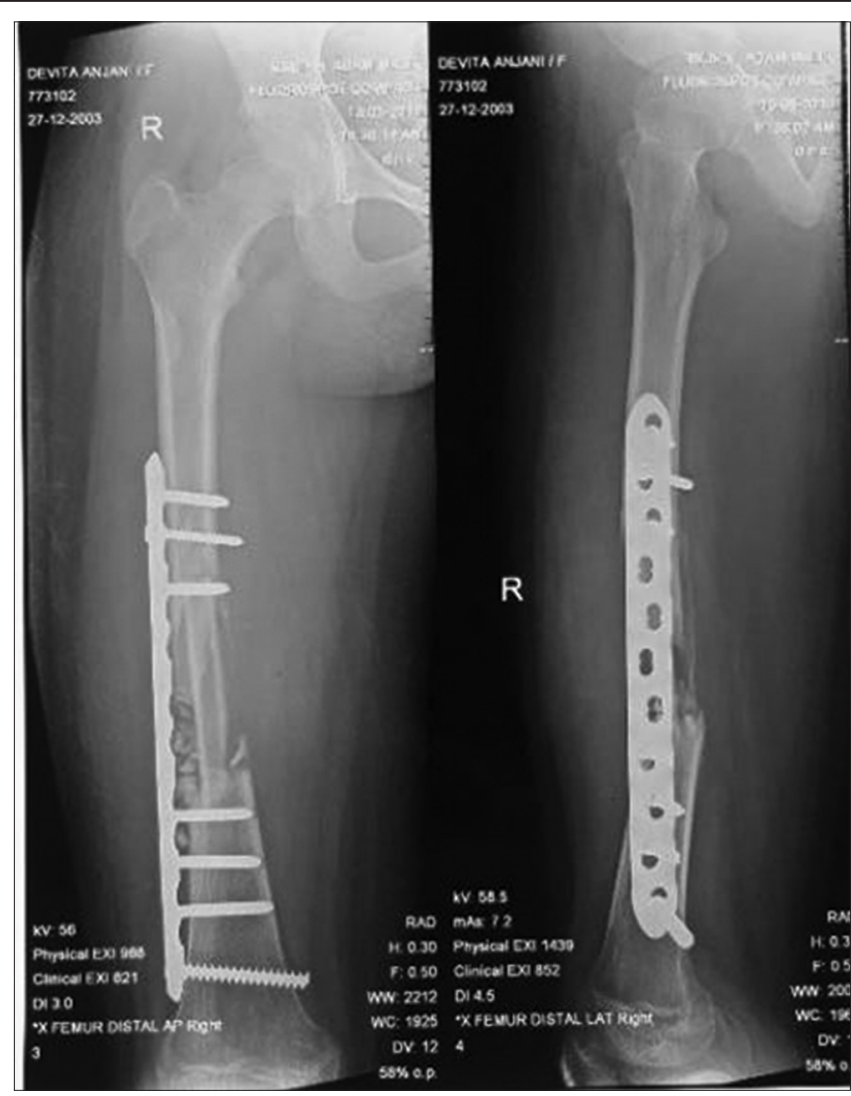

Figure 4: 8 weeks after operation radiographs

Table 1: ROM after 32 weeks

\begin{tabular}{ll}
\hline HIP & \\
Flexion & $140^{\circ}$ \\
Extension & $10^{\circ}$ \\
Abduction & $40^{\circ}$ \\
Adduction & $30^{\circ}$ \\
Internal Rotation & $55^{\circ}$ \\
External Rotation & $45^{\circ}$ \\
KNEE & \\
Flexion & $140^{\circ}$ \\
Extension & $0^{\circ}$ \\
\hline
\end{tabular}

Table 2: Leg length measurement

\begin{tabular}{lll}
\hline Leg length & Right $(\mathrm{cm})$ & Left $(\mathrm{cm})$ \\
\hline True length & 77 & 77 \\
Apparent length & 83 & 83 \\
Anatomical length & 42 & 42 \\
\hline
\end{tabular}

The patient begun partial weight bearing in 8 weeks, full weight bearing in 24 weeks, and finally the patient can walk without using crutches and has no problems in a squatting position.

\section{Case 2}

A 37-year-old male patient was admitted to the emergency department due to a traffic accident while riding a motorcycle on may. A few days later the patient comes and complaint of pain in his right thigh, where implant failure of the femur was noted during X-ray, and reoperation was performed on occasions.

Another episode of pain was noted 4 days after the first reoperation of the femur, and then one year later his right femur (Figures 7 and 8).

On June 2019, perform removal of the implant and during the operation was discovered the fibrotic tissue and diaphyseal defect of femur $10 \mathrm{~cm}$, majority 
of defect arise from the lateral site and little part of the diaphysis in the medial site.

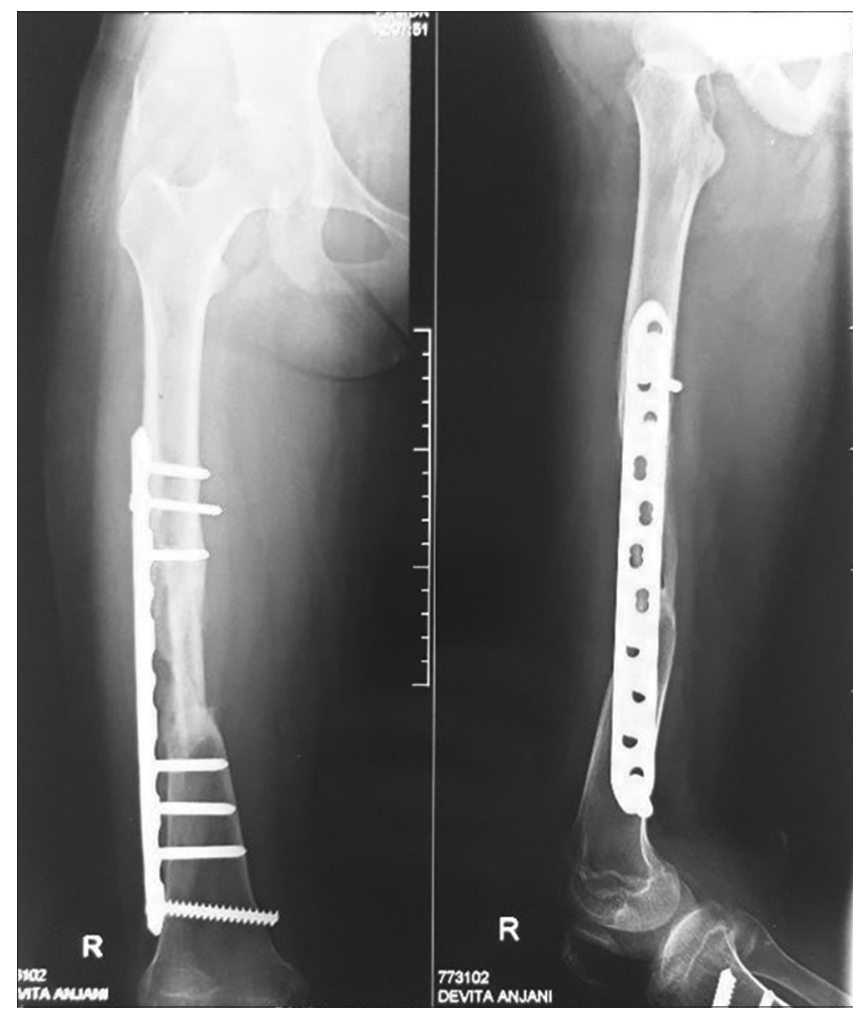

Figure 5: $X$-ray femoral $A P / L$ and post open reduction internal fixation

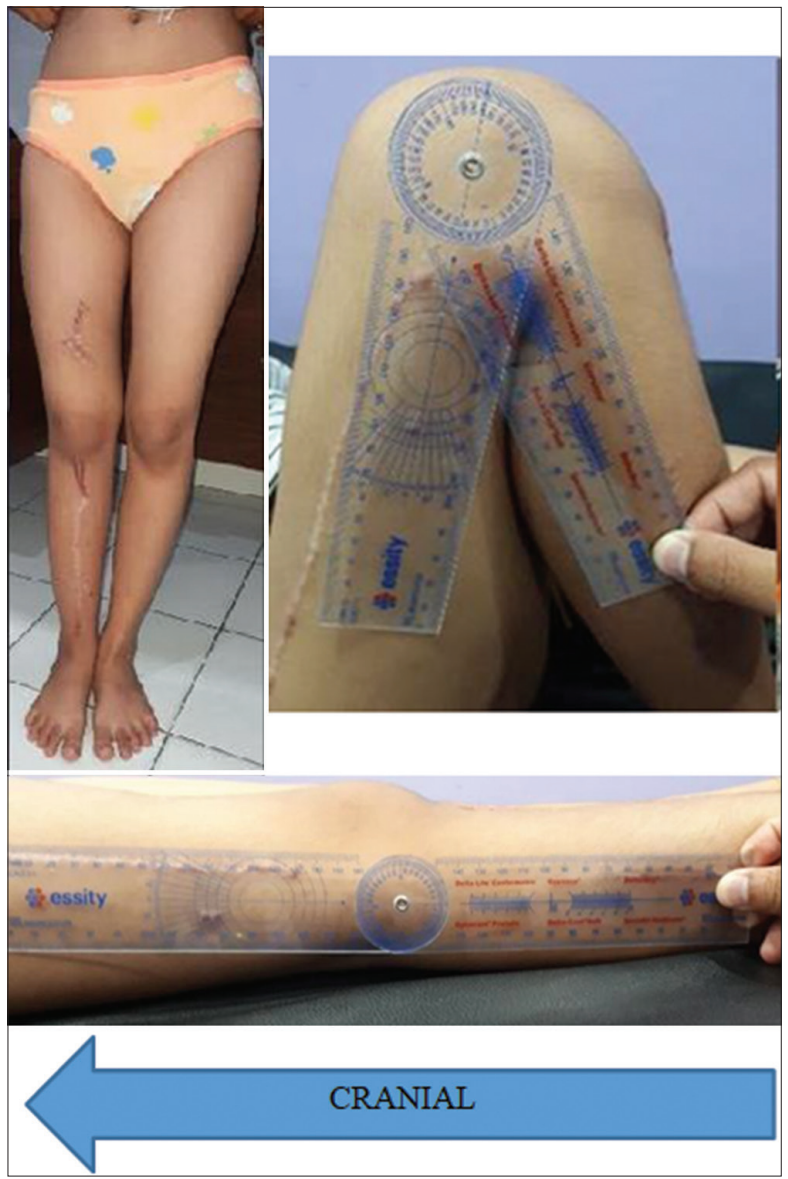

Figure 6: Clinical examination in 32 weeks, there was no leg length discrepancy

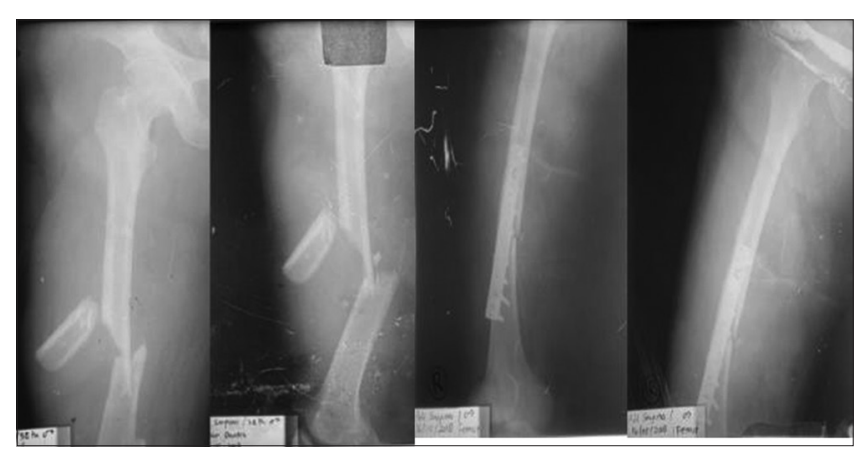

Figure 7: X-ray femoral AP/L and post open reduction internal fixation

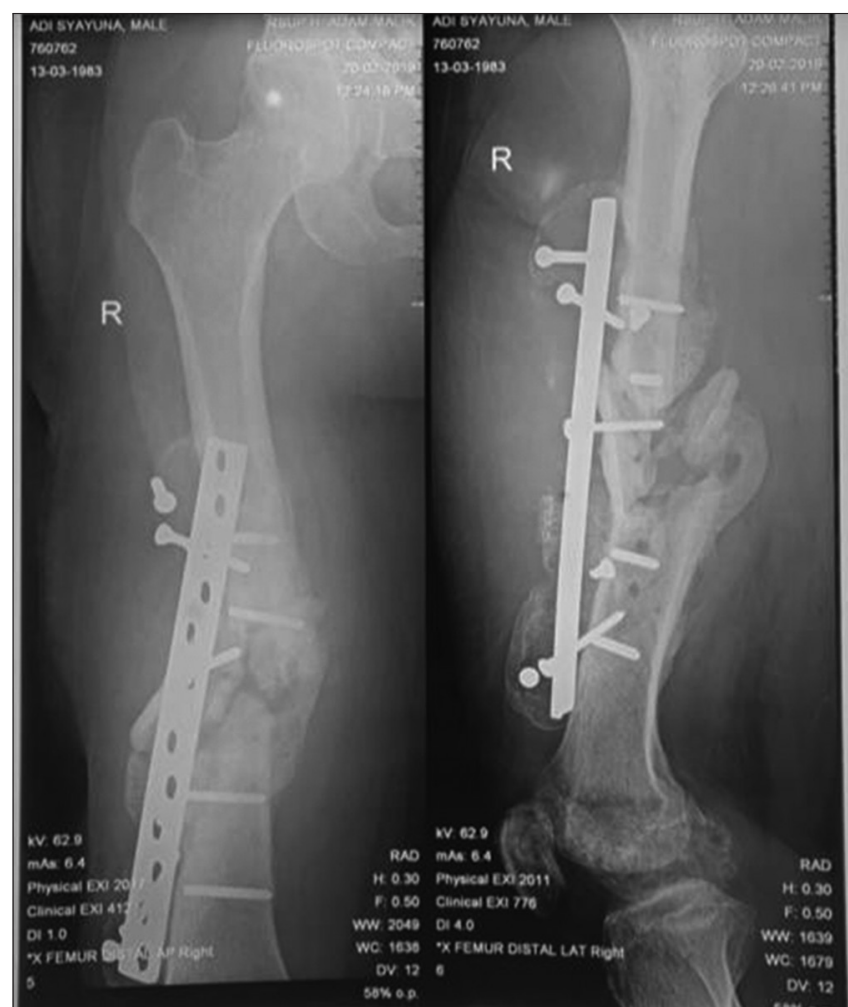

Figure 8: X-ray before operation with implant failure and nonunion

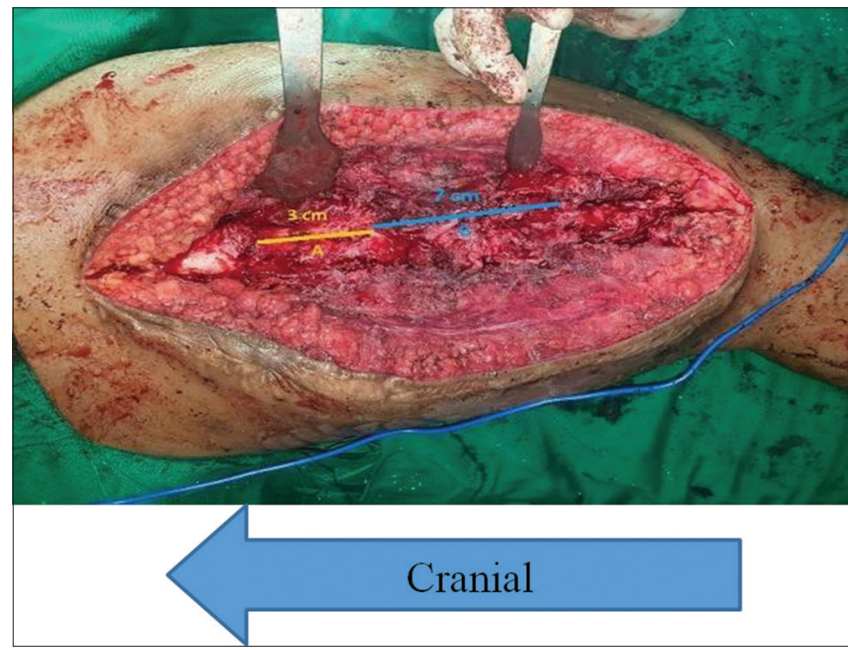

Figure 9: During operation show defect bone: (a) Remaining partial bone in posteromedial side by defect $3 \mathrm{~cm}$ (b) missing total bone in the shaft femur by defect $7 \mathrm{~cm}$

Using non-vascularized autologous fibular graft, iliac graft, and synthetic bone graft for internal fixation with femoral locking plate method was considered. Immediate 
reconstruction with a massive bone autograft was preferred because it would allow rapid weight-bearing. A $10 \mathrm{~cm}$ bone graft was fixed by an internal fixation femoral locking plate. The length of the reconstruction was based on the opposite femur (Figures 9 and 10).

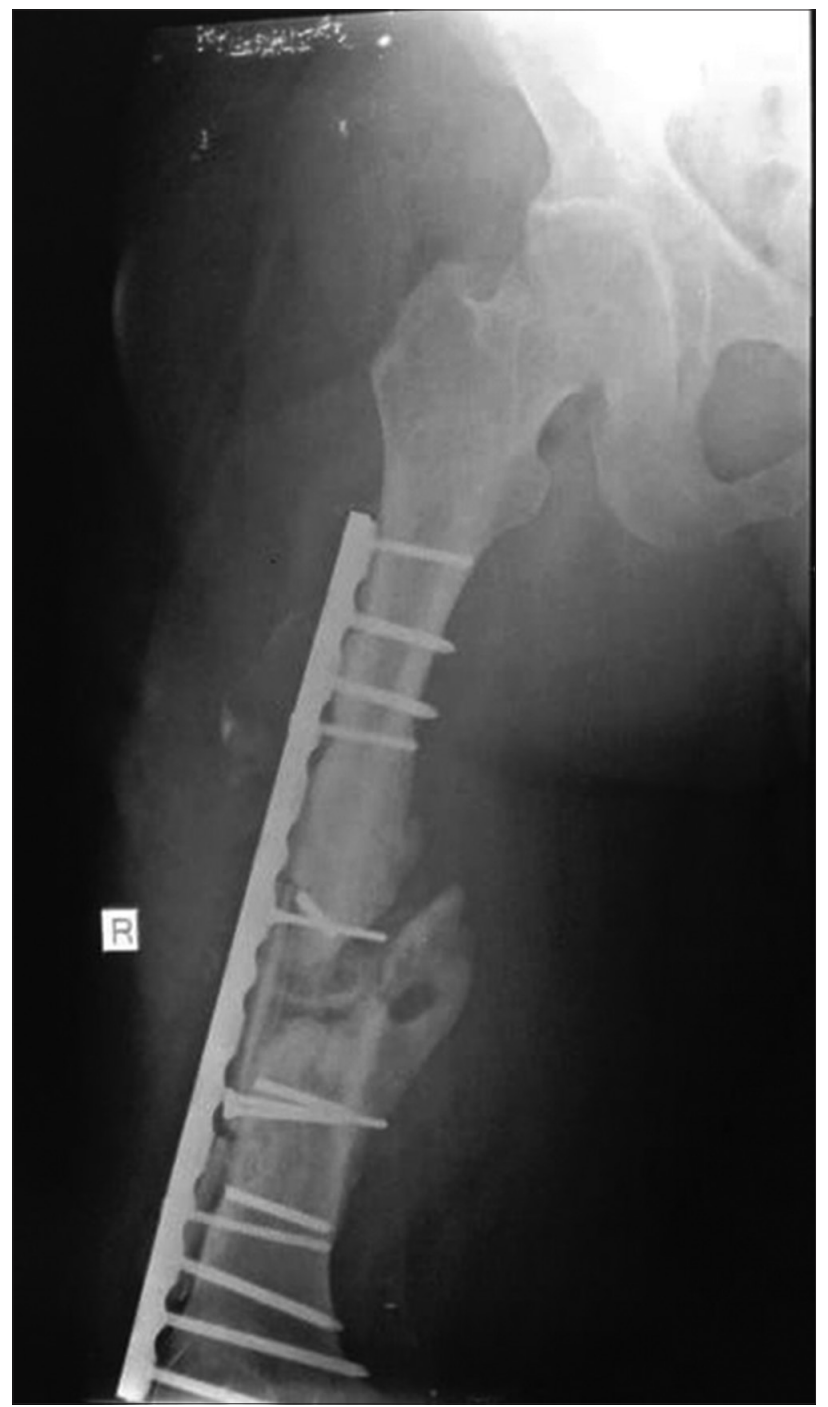

Figure 10: X-ray of the last non-vascularized autologous fibular graft with the internal fixation, bone callus formation is noted, and thinning of fracture gap

\section{Results}

The patient has a good result with good functional outcome (Tables 3 and 4 ) after open reduction internal fixation and using a non-vascularized autologous fibular graft for treating the major bone defect after posttraumatic femoral shaft fracture (Figures 11-13).

\section{Discussion}

The prevalence of femoral shaft fractures is approximately 10 per 100.000 people with peak-age related incidence between the ages of 15-24 years [11]. The early reference stated that vascularized bone graft offer significant advantages over conventional treatment methods in selected patients with segmental bone defects greater than $6 \mathrm{~cm}$ [12]. For defects of $>12 \mathrm{~cm}$, vascularized grafts are superior to non- vascularized grafts as indicated by failure rates of $25 \%$ and $50 \%$, respectively [13]. In our case, we are using cortical autologous bone graft because it would allow rapid weight-bearing and fasten the mobilization.

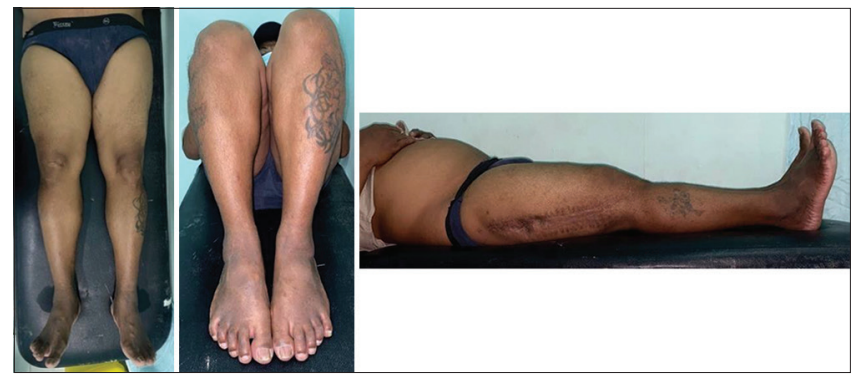

Figure 11: Leg length discrepancy was noted during clinical examination

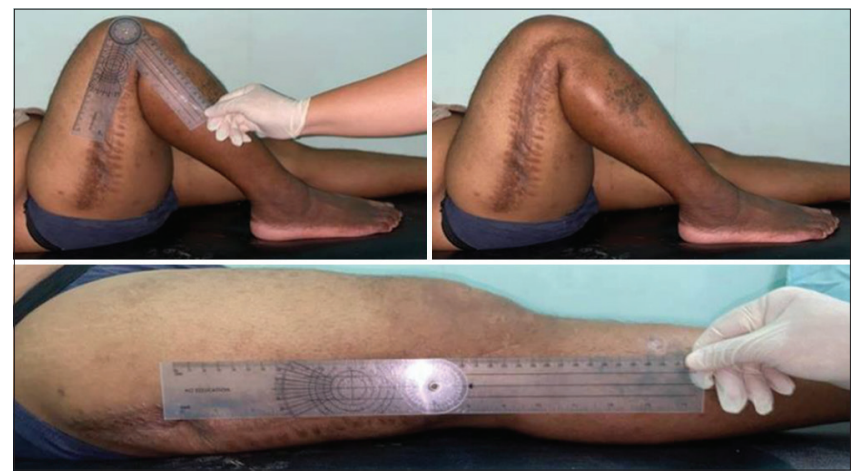

Figure 12: Flexion and extension of the knee with a good results
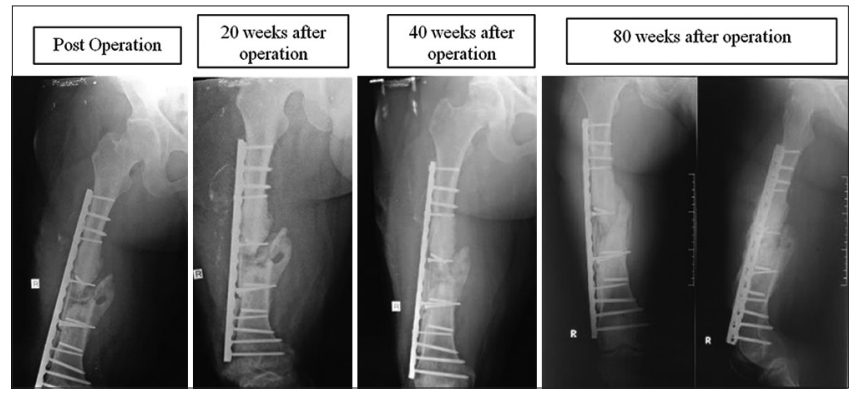

Figure 13: Radiographic control post-operation

Another study also showed that vascularized cortical grafts healed more rapidly at the site of grafthost interface and their remodeling capability was similar to that of a normal bone. Unlike non-vascularized grafts, these grafts do not undergo resorption and revascularization and therefore they provide superior strength during the first 6 weeks but have potential non-union $>6 \mathrm{~cm}$ [14]. In our case, the bone defect $>6 \mathrm{~cm}$ and we are using fibular graft and into the femoral medullary cavity and having a good outcome. Despite their initial strength, cortical grafts still must be supported by internal or external fixation to protect them from fracture while they hypertrophy in response to Wolff 's law and mechanical loading [15], so we 
decided to using internal fixation to increase response to Wolff's law, in the 24 months we found a bridging callus, it is same effective such as vascularized cortical grafts. Bone gaps could resulted from atrophic nonunion. They are characterized by poor blood supply. Non- vascularized fibular bone graft might took longer time to achieve union, but if used in good vascular bed and soft tissue coverage, it could obtained a similar result to the vascularized fibular bone-graft [16].

Table 3: Leg length discrepancy measurement

\begin{tabular}{lll}
\hline Leg length & Right $(\mathrm{cm})$ & Left $(\mathrm{cm})$ \\
\hline True Length & 95 & 96 \\
Apparent Length & 84 & 85 \\
Anatomical Length & 38 & 39 \\
\hline
\end{tabular}

Anatomical Length

Table 4: Range of motion

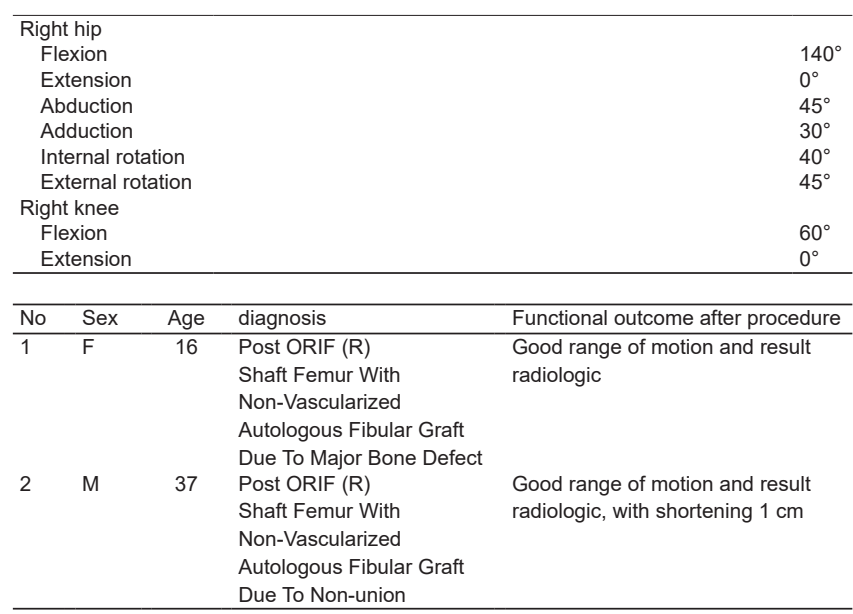

Studies by Azam et al. [17] and Elgeidi and El-Negery [18] concluded that non-vascularized fibular bone graft gave a satisfactory outcome and less demanding procedure in femoral fracture in both children and young adults. In our case series, the good result happened in a 16-year-old woman and a 37-year-old man with complete union of the non- vascularized fibular graft and almost complete range of motion at the hip and knee joint. Tall et al. [19] conducted a study about treating non-union in neglected long bone fractures by osteo- periosteal decortication which they reported 2 cases of leg length differences. Study by Zhang et al. [20] investigated monoliteral external fixation as an alternative method for treating femoral non-union with large bone defect. From 41 patients, there are three cases of axial deviations, five cases of docking site nonunion, 23 pin- tract infection cases, 14 knee joint stiffness cases, two osteogenesis insufficiency cases, one refracture case, and two cases of loose external fixation pin, complete and comprehensive debridement surgery with autologous non- vascularized fibular graft, stabilized fracture with LC-DCP allow an early rehabilitation. Early mobilization combined with strengthening activities after surgical treatment of femoral shaft fracture in adults may result in early resolution of impairments and functional limitations and decreased disability [21]. Physiotherapy and early mobilization would result in better outcome for the patient, all of these are less expensive and widely reproducible options to manage bone defects in complex open shaft femoral fractures in order to achieve union, preserving length and motion with no donor site morbidity and giving patients good functional outcome.

\section{Conclusion}

We followed the patient for 32 weeks and 80 weeks have a good outcome, the bony defects arising out of post-traumatic bone major defect can be successfully reconstructed with fibular graft-giving good functional outcome. However, these bony defects can be successfully managed with fibular reconstruction when they present early to the surgeon. Our overall experiences with non- vascularized fibular graft for reconstruction bony defects are encouraging; however, this method could be an alternative treatment for treating a post-traumatic bone major defect in adolescents if used in good vascular bed and soft tissue coverage in a hospital that has no subspeciality, we are aware this is a short-term study and would require further evaluation and more inputs.

\section{References}

1. Lawal $Y Z$, Garba ES, Ogirima MO. Use of non-vascularized autologous fibula strut graft in the treatment of segmental bone loss. Ann Afr Med. 2011;10(1):25-8. https://doi. org/10.4103/1596-3519.76571

PMid:21311151

2. El-Sayed M, El-Hadidi M, El-AdI W. Free nonvascularized fibular graft for treatment of post-traumatic bone defects. Acta Orthop Belg. 2007;73(1):70-6.

PMid:17441661

3. Masquelet AC, Begue T. The concept of induced membrane for reconstruction of long bone defects. Orthop Clin North Am. 2010;41(1):27-37. https://doi.org/10.1016/j.ocl.2009.07.011 PMid:19931050

4. Masquelet AC, Fitoussi F, Begue T, Muller GP. Reconstruction of the long bones by the induced membrane and spongy autograft. Ann Chir Plast Esthet. 2000;45(3):346-53.

PMid:10929461

5. Masquelet AC. Muscle reconstruction in reconstructive surgery: Soft tissue repair and long bone reconstruction. Langenbecks Arch Surg. 2003;388(5):344-6. https://doi.org/10.1007/ s00423-003-0379-1

PMid:13680234

6. Thakkar CV, Dwivedi MS. Open distal femur fractures: Treatment principles. Int J Orthop Sci. 2018;4(4):732-6. https:// doi.org/10.22271/ortho.2018.v4.i4i.89

7. Dinh P, Hutchinson BK, Zalavras C, Stevanovic MV Reconstruction of osteomyelitis defects. Semin Plast Surg. 2009;23(2):108-18.

PMid:20567733

8. Yajima $\mathrm{H}$, Tamai $\mathrm{S}$, Mizumoto $\mathrm{S}$, Inada $\mathrm{Y}$. Vascularized fibular grafts in the treatment of osteomyelitis and infected 
nonunion. Clin Orthop Relat Res. 1993;293:256-64. https://doi. org/10.1097/00003086-199308000-00033

\section{PMid:8339489}

9. Sun $Y$, Zhang $C$, corresponding author Dongxu Jin, Jiagen Sheng, Xiangguo Cheng, Xudong Liu, Shengbao Chen, and Bingfang Zeng. Free vascularised fibular grafting in the treatment of large skeletal defects due to osteomyelitis. Int Orthop. 2010;34(3):425-30. https://doi.org/10.1007/ s00264-009-0761-x

PMid: 19308407

10. Lenze $U$, Kasal S, Hefti F, Krieg AH. Non-vascularized fibula grafts for reconstruction of segmental and hemicortical bone defects following meta-/diaphyseal tumour resection at the extremities. BMC Musculoskelet Disord. 2017;18(1):289. https:// doi.org/10.1186/s12891-017-1640-z PMid:28679368

11. Xiong R, Mai QG, Yang CL, Ye SX, Zhang X, Fan SC et al. Intramedullary nailing for femoral shaft fractures in adults. Cochrane Database Syst Rev. 2013;5:1-4. https://doi. org/10.1002/14651858.cd010524

12. Weiland AJ, Moore JR, Daniel RK. Vascularized bone autografts. Experience with 41 cases. Clin Orthop RelatRes. 1983;174:87-95. https://doi.org/10.1097/00003086-198304000-00010 PMid:6339145

13. Gazdag AR, Lane JM, Glaser D, Forster RA. Alternatives to autogenous bone graft: Efficacy and indications. J Am Acad Orthop Surg. 1995;3(1):1-8.

PMid:10790647

14. Dell PC, Burchardt H, Glowczewskie FP Jr. A roentgenographic, biomechanical, and histological evaluation of vascularized and non-vascularized segmental fibular canine auto-grafts. J Bone Joint Surg Am. 1985;67(1):105-12. https://doi. org/10.2106/00004623-198567010-00013

PMid:3881445
15. Doi K, Tominaga S, Shibata T. Bone grafts with microvascular anastomosis of vascular pedicles: An experimental study in dogs. J Bone Joint Surg Am. 1977;59(6):806-15. https://doi. org/10.2106/00004623-197759060-00015

PMid:908705

16. Shah KB, Kamath J, Jayasheelan N, Danda R, Rai MK. Nonvascularized fibular strut grafting in management of bone defects. Online J Health Allied Scs. 2015;14(4):14.

17. Azam MQ, Iraqi AA, Sherwani M, Sabir AB, Abbas M, Asif $N$ Free fibular strut graft in neglected femoral neck fractures in adult. Indian J Orthop. 2009;43(1):62-6. https://doi. org/10.4103/0019-5413.45325

PMid: 19753182

18. Elgeidi A, El-Negery A. Fibular graft for non-united femoral neck fractures in children. J Child Orthop. 2017;11(1):28-35. https:// doi.org/10.1302/1863-2548-11-160221

PMid:28439306

19. Tall M, Bonkoungou D, Sawadogo M. Treatment of nonunion in neglected long bone shaft fractures by osteoperiosteal decortication Orthop Traumatol Surg Res. 2014;100 Suppl 6:S299-303. https://doi.org/10.1016/j. otsr.2014.07.005

PMid:25193620

20. Zhang Q, Zhang W, Zhang Z, Zhang L, Chen H, Hao M, et al. Femoral nonunion with segmental bone defect treated by distraction osteogenesis with monolateral external fixation. J Orthop Surg Res. 2017;12(1):183. https://doi.org/10.1186/ s13018-017-0684-y

PMid:29178906

21. Paterno MV, Archdeacon MT, Ford KR, Galvin D, Hewett TE. Early rehabilitation following surgical fixation of a femoral shaft fracture. Phys Ther. 2006;86(4):558-72. https://doi.org/10.1093/ $\mathrm{ptj} / 86.4 .558$

PMid: 16579672 